\title{
Management of Hip Labral Tears in Athletes: An Evidence-Based Review of the Literature
}

\author{
Walid Ben $\mathrm{Nafa}^{1,2 *}$ \\ ${ }^{1}$ School of Health Sciences, The University of Salford, UK \\ ${ }^{2}$ Department of Trauma \& Orthopaedics, Manchester University NHS Foundation Trust, UK
}

Submission: May 21, 2018; Published: May 29, 2018

*Corresponding author: Walid Ben Nafa, School of Health Sciences, University of Salford, UK, Email: W.O.Ben-nafa@edu.salford.ac.uk

\begin{abstract}
Hip labral tears have been increasingly regarded as a major cause of hip pain and disability among the athletes. Besides the traumatic nature of this injury, different hip pathologies can be associated with its occurrence. Various modes of management are available for the management of labral tears. However, limited evidence is found to support theses treatment options, especially when it comes to conservative management. Surgical option appears to be the most accepted management option, with more evidence available to support its use in the literature. While debridement was considered as a main surgical option, increasing evidence about its detrimental effect on the hip joint, especially on the longterm were noted. Conversely, there is a growing interest in preserving the acetabular labrum using repair/re-attach techniques, with potentially better outcomes observed compared to the debridement option. Proper evaluation of the patient's condition including any concomitant pathology as well as the type and location of the labral tear must be duly considered, as these are important factors when deciding the management option.
\end{abstract}

Keywords: Hip/Groin pain; Labral tear; Sportsmen; Athletes; Conservative management; Biomechanics; Surgery; Arthroscopy; Debridement; Excision; Re-fixation; Repair

Abbreviations: FAI: Femoro-Acetabular Impingement; MRA: Magnetic Resonance Arthrography; HHS: Harris Hip Scores

\section{Introduction}

The acetabular labrum is a complex fibro cartilaginous ring which is attached circumferentially to the bony rim of the acetabulum [1] (Figure 1). While its function is not fully understood, the labrum's unique anatomical structure plays a role in hip joint stability, as well as reducing the articular contact stress by distributing the load, partly through the sealing mechanism of the synovial fluid [2]. Any tear in this distinctive structure leads to a disruption in the sealing effect, with possible subsequent joint deterioration [2]. While further research is needed to determine the prevalence of labral tears among the public, some evidence showed that labral tear has a prevalence of around $66 \%$ among patients with mechanical hip pain [3].
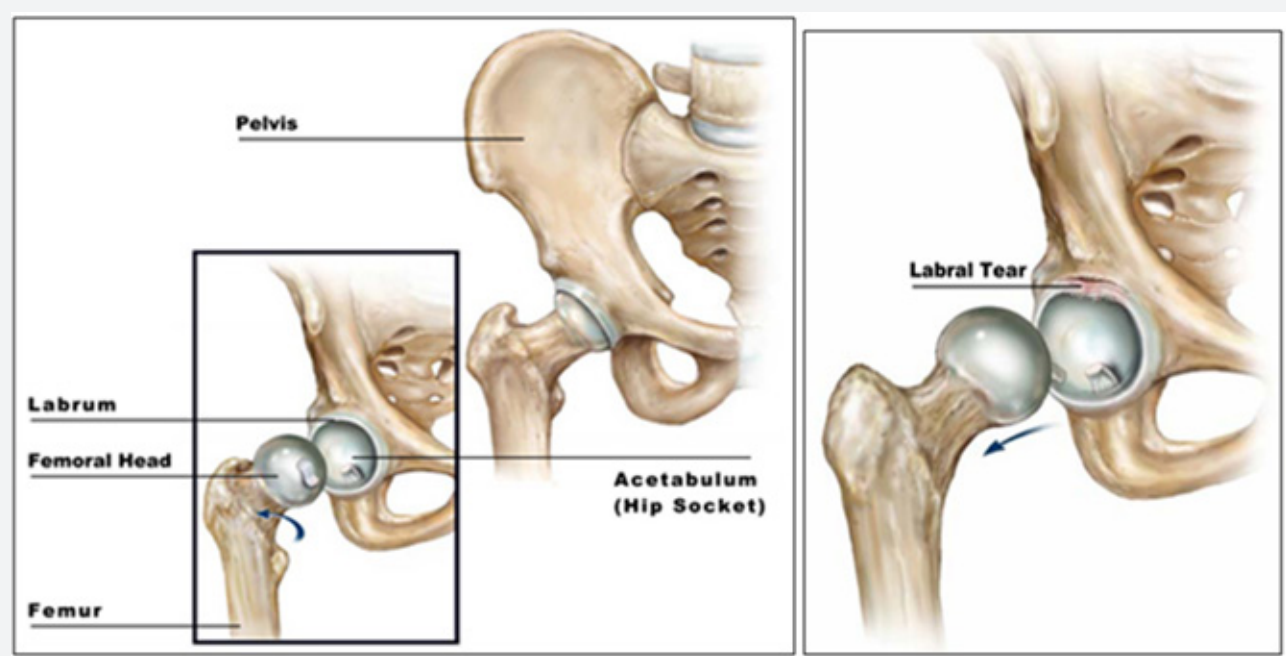

Figure 1: Anatomical illustration of acetabular labral tear in relation to the hip joint" [4]. 
Acetabular labrum is susceptible to traumatic injuries in response to different shearing forces caused by various hip movements including twisting, falling and pivoting [5]. Labral tears among athletes can be caused by an isolated traumatic event or from repetitive trauma to the acetabular labrum [6]. Some traumatic injuries including hip dislocations and acetabular fractures can also be associated with acetabular labral tears [7]. In addition, a number of hip pathologies can be responsible for or associated with the occurrence of labral tears including femoro-acetabular impingement (FAI), hip hypermobility, retroverted acetabulum, coxa valga and articular cartilage injuries [8-10].

Due to the improvements in diagnostic methods, there has been an increasing awareness of acetabular labral tear as a potential cause of hip pain $[2,11]$. Different clinical symptoms can be experienced by patients with labral tears including groin/ hip pain, limping, limited hip joint movements, and mechanical symptoms including locking, catching or giving way [9]. Before considering the treatment options used for the management of hip labral tear, full clinical assessment is the initial and indispensable step to determine the source of hip pain in this patient [12], including a comprehensive medical history of any previous hip joint problems. Imaging modalities including radiographic evaluation (X-ray) is used initially to detect structural abnormalities of the hip and pelvis [10]. Magnetic resonance arthrography (MRA) can provide a detailed study of the acetabular labrum, with its diagnostic reliability and sensitivity of more than $90 \%[13,14]$. Arthroscopy on the other hand, and beside its use in the surgical managing labral tears, is considered the most reliable mode to diagnose acetabular labral tears [15].

\section{Management of Labral Tears}

To date, most of the available studies on labral tears management were observational. While there are some systematic reviews with good methodology, scarce or no interventional randomised controlled studies are available in the literature. This could be partly due to the difficulty in masking the interventional modes of managements such as physiotherapy, when allocating patients to control and interventional groups for example. In addition, randomising the patients to conservative versus surgical treatments for example, to compare the clinical outcomes, could be difficult, as some variables including the site of the tear, type of injury and the presence of concomitant pathologies can affect the management plan on whether to treat the injuries conservatively or surgically.

\section{Conservative Management}

When a diagnosis of labral tear is established, it is typically advised that a trial of conservative non-invasive management including rest, restriction of weight bearing and non-steroidal anti-inflammatory medications, are considered to be the first treatment lines [10]. In addition, a course of physiotherapy including modifications of functional activities, muscles strengthening and restricting some movements including pivoting motions might be useful $[2,10]$. However, and while the pain can be reduced following these physiotherapeutic measures, It has been shown that once the patient returns to his normal level of activity, the pain recurs consequently [2]. Thus, physiotherapy may not be the ultimate and definitive management for athletes who are expecting to resume their sport activity with its physically-demanding nature and/or extreme hip movements. Furthermore, only scarce evidence about the therapeutic effect of conservative management are available, which are mostly anecdotal/experts' opinions or case series of small numbers $[2,16]$.

One of the other non-surgical treatment options of acetabular labral tears is the injection therapies. Again, smallscale evidence is available about the efficacy of this treatment for the management of hip labral tears. In a case series of 19 patients with labral lesions who were injected with hypertonic dextrose, Hauser \& Orlofsky [17] suggested that this mode of management is a safer and effective procedure [17]. Although some improvements were observed, this could have been caused by the placebo effect of the injection given or the spontaneous improvement of the condition, especially with the absence of control group to assess the comparative effect of the treatment given.

\section{Surgical Management}

With a significantly greater evidence about its outcomes compared to the other conservative treatments, surgery is considered a main treatment line for labral tears, and often considered the mode of management when the patient's symptoms does not resolve conservatively or when failed or unsatisfactory results of conservative treatments are encountered $[2,10]$. Persistent symptoms and late diagnosis of labral tears appear to be good indications for surgical management $[8,18]$. Furthermore, surgical management, especially labral-preserving procedures, aims to preserve the labrum which is known for its evidence-based function in preventing premature arthritis and enhancing joint stability [19]. On the other hand, surgical management could be the best option for patients with other known concomitant hip/acetabular structural abnormalities which can be addressed simultaneously, especially that it was shown that the combined effect of managing hip abnormality and labral tears can provide the best outcome to the patients [2].

Beside the fact that peripheral tears are more amenable to repair due to the relatively higher vascularity, the type of tear itself can have a role when deciding the management plan. Detached labrum can be managed by suture anchors, attached labrum with a secure outer rim can be repaired by a suture in the labral substance itself, whereas degenerative or unviable labral tissues are better to be debrided [19]. In addition, any chondral lesions which are concomitantly found adjacent to the labral injury can be managed by debridement, microfracture or cartilage resurfacing 
[20]. Many of the above-mentioned surgical techniques can be performed using arthroscopy. As a minimally invasive procedure which is used to treat various abnormalities of the hip, and with less tissue damage and shorter recovery time, arthroscopy might be the most appropriate and feasible management option [11]. It has been demonstrated that there is a growing list of surgical applications for the use of hip arthroscopy in the management of symptomatic acetabular labral tears, with observed long-term efficacy [21]. Arthroscopy can also be considered as the golden measure to confirm the diagnosis and to manage the labral tear simultaneously [8]. However, patient's condition as well as any potential concomitant hip pathologies should be considered, as these might affect the management option used in treating the condition.

\section{Debridement Versus Repair}

Surgical debridement is one of the options used in treating labral injuries. In a systematic review conducted by Robertson et al. [11] to evaluate arthroscopic debridement as a surgical option [11], a significantly high satisfaction rate was observed post-operatively in $67-91 \%$ of patients. Nonetheless, some participants in some studies of this review had received some treatments before their participations in the studies, and this can be considered as a confounding factor when evaluating the therapeutic outcomes of this surgical technique. This is in addition to the heterogeneity of the studies reviewed, with the different outcome measures used. It is also worth mentioning here that a number of the participants of some of the included studies in this review, who were diagnosed with other specific concomitant hip pathologies or severe disease, have been excluded, which limits the outcome conclusions drawn by this review. The effects of these concomitant hip abnormalities on the therapeutic outcomes were clearly noted by Meftah et al. [22], who concluded that unless coexisting hip abnormalities were managed in affected patients, therapeutic effect of arthroscopic debridement will be affected as a result of these concomitant pathologies [22]. In their study with a mean follow-up of about 8.5 years, higher Harris hip scores (HHS) were noticed in patients without co-existing hip abnormalities. Conversely, labral tear cases with arthritis and FAI lesions were associated with significantly lower HHS, where only $19 \%$ of patients with arthritis for example have a HHS of 90 or over. Nevertheless, these low levels of dissatisfactions could have been caused by the arthritic changes or the pathologies of the hip themselves, rather than a direct result of labral debridement or newly evolving pathologies. Also, not to forget that despite the popular use of HHS, this outcome measure was originally and specifically designed to assess the outcomes of hip arthroplasty. It is also notable that the participants in this study were treated previously with other conservative management including physiotherapy and hip injections, which again could have provided some degree of symptomatic improvement to these patients. All these evidence-based facts about the concomitant hip pathologies and their potential effects post-operatively should be duly explained to the affected sportspersons before considering any treatment option.

Recently, there has been an increasing interest in preserving the acetabular labrum in various hip joint procedures, mainly due to the ongoing advancements in arthroscopic instruments and techniques $[23,24]$. Increasing number of studies have been focusing on preserving the acetabular labrum through repair and re-fixation, where superior results have been noticed [19,25]. In a retrospectively conducted study, the comparative effects of debridement against the re-fixation management of labral tears associated with FAI lesions were evaluated. Larson \& Giveans [26] concluded that refixation resulted in better clinical outcomes with higher HHS compared to the debridement group results [26], although only a relatively short-term follow-up between 1-2 years was considered. Also, the improvement with the refixation group could be resulted from the improved techniques and instrumentation, as the refixation procedures noted to be conducted many years after the debridement procedures. With small study population of 36 hips for debridement and 39 for refixation, and the use of historical control (debridement group), the conclusions drawn from this level III comparative study should be interpreted with caution, and further studies investigating this management option should be consulted.

From a biomechanical perspective, where the study of the mechanics and forces acting on the hip joint is of a paramount important, the increase in the chondral load associated with labral debridement could be another discouraging factor when considering surgical debridement in sportspeople. Greaves et al. [27] conducted a study to evaluate the effect of labral debridement versus repair on the hip articular cartilage [27]. While it was performed on cadaveric models, it showed a significant decrease in the mean cartilage strain when labral repair was conducted, compared to labral resection, which was associated with even a higher load compared to the unmanaged labral tears. Although it was a simulated study where the labral structure was purposely torn, and despite the small study number, the findings can give some perspective about how different interventions on the acetabular labrum can lead to a significantly different biomechanical effects on the surrounding structures. The same biomechanical principle of this study could provide more reliable results if this was applied on interventional or at least prospective studies, where chondral load can be assessed peri-operatively on patients who had debridement or repair surgeries.

While the previous studies discussed the effect of labral repair versus debridement surgery, the location and the type of labral tear in terms of its status/quality should be considered too, as repair surgery is not always the definitive management. Haddad et al. [28] suggested that re-fixations should not be a routine procedure in managing labral tears, as the status of the injured labrum itself should be considered as a major factor in deciding the best surgical option [28]. The authors conducted 
a systematic review of 28 studies to analyse the outcomes of debridement versus re-attachment procedures [28]. Significantly good results were observed in the both groups, with relatively better outcomes in the reattachment group using modified HHS. The researchers however, concluded that the location and type of tear are considered as important factors in estimating the healing potential, where peripheral tears or good-quality unstable labrum are more repairable and has potentially a better chance to heal. With the lack of randomisation, selection bias is possible in some of the included studies, as cases allocated for repair might have had less degenerative changes or labral damage, and vice versa. Moreover, high rates of drop-out, small number of patients in some studies and the recall bias in retrieving participants' data regarding the clinical outcomes, necessitate that larger high-quality comparative studies with long-term follow-up can provide more reliable results. While no strong evidence can be deducted from this review, it can be observed that beside the tear location, unstable labrum of a good quality is better to be repaired, whereas degenerative or calcified labrum should be debrided or carefully assessed if a reparative procedure is planned, as there is a potential failure of re-attachment with persistent hip pain.

\section{Arthroscopic-Related Complications}

Finally, with the increasing use of hip arthroscopy in performing many of the surgical techniques used for treating labral tears, the risk/benefit element should also be briefly highlighted here. Although hip arthroscopy is a less invasive technique compared to open surgery, some surgical complications are found to be associated with its use. While these complications are generally related to inappropriate portal placements and prolonged limb traction [29], and beside the well-known general surgical complications such as infection and neurovascular injury, other arthroscopic-related complications have been noted. These include fluid extravasation into anatomical spaces, heterotopic ossification, labral injury during suture repair, and perineal pressure necrosis and injury [30-32]. These potential complications should be remembered and communicated to the patient, although most of them are transient in nature and relatively of low incidence $(0.5-5 \%)[30,33]$.

\section{Post-Operative Rehabilitation}

Although surgical outcomes of labral tears have been evaluated in the literature, scarce or no attention have been given to post-operative rehabilitation and its effect on patients [34]. Patients need to be advised about the post-operative rehabilitation as an important factor when managing labral tears, as non-compliance with a proposed post-operative rehabilitation program may affect the surgical intervention and its outcome [15]. Post-operative tailored multi-staged rehabilitation programme according to the patient's underlying pathology and surgical procedure appears to be effective to help patients to return to a competitive level of sports activity [35]. However, the best evidence for postoperative rehabilitation protocols is relatively lacking in the literature, where rehabilitation programmes are still dependant on experts opinions including therapist/surgeon experiences. Thus, more evidence is still needed to fully validate the long-term results of rehabilitation protocols post-operatively [36].

\section{Conclusion}

Acetabular labral tear has been increasingly considered as a major cause of hip pain and disability among the athletic population. While it can be traumatic in nature, various hip pathologies can be associated with its occurrence. Different modes of management have been proposed for the management of labral tears. Nonetheless, limited or no evidence is found to support conservative treatments including physiotherapy and prolotherapy. To date, surgical option appears to be the most accepted management option, with more available evidence about its therapeutic effect in the literature. While debridement was considered one of the best procedures used, there is recently increasing evidence about its detrimental effect on the hip joint, especially on the long-term. Conversely, there is a growing interest in preserving the acetabular labrum with potentially better outcomes, compared to the debridement procedure; as well as the labral effect in restoring and preserving the joint integrity and structures. Accurate assessment of the patient condition including any concomitant pathology as well as the type and location of the labral tear must be properly considered, as these are important factors when deciding the management option. High-quality studies with validated outcome measures are still lacking in the literature. Future research works should include comparative studies of larger size to provide more accurate evaluation of the outcomes of the different therapeutic options used in the management of labral tears.

\section{References}

1. Shindle MK, Voos JE, Nho SJ, Heyworth BE, Kelly BT (2008) Arthroscopic Management of Labral Tears in the Hip. The Journal of Bone \& Joint Surgery 90(4): 2-19.

2. Lewis CL, Sahrmann SA (2006) Acetabular labral tears. Physical Therapy 86(1): 110-121.

3. Neumann G, Mendicuti AD, Zou KH, Minas T, Coblyn J, et al. (2007) Prevalence of labral tears and cartilage loss in patients with mechanical symptoms of the hip: Evaluation using MR arthrography. Osteoarthritis and Cartilage 15(8): 909-917.

4. Arthroscopic Hip Surgeon (2011) Hip Arthroscopy. Retrieved 20 May 2018, from http://www.arthroscopichipsurgeon.com/hiparthroscopy.html.

5. Martin RL, Enseki KR, Draovitch P, Trapuzzano T, Philippon MJ (2006) Acetabular labral tears of the hip: Examination and diagnostic challenges. Journal of Orthopaedic \& Sports Physical Therapy 36(7): 503-515.

6. Bharam S (2006) Labral tears, extra-articular injuries, and hip arthroscopy in the athlete. Clinics in Sports Medicine 25(2): 279-292.

7. Stabile KJ, Neumann JA, Mannava S, Howse EA, Stubbs AJ (2014) Arthroscopic Treatment of Bucket-Handle Labral Tear and Acetabular Fracture. Arthroscopy Techniques 3(2): e283-e287.

8. Wenger DE, Kendell KR, Miner MR, Trousdale RT (2004) Acetabular labral tears rarely occur in the absence of bony abnormalities. Clinical Orthopaedics and Related Research 426: 145-150. 
9. Burnett RS, Della Rocca GJ, Prather H, Curry M, Maloney WJ, et al. (2006) Clinical presentation of patients with tears of the acetabular labrum. The Journal of Bone \& Joint Surgery 88(7): 1448-1457.

10. Groh MM, Herrera J (2009) A comprehensive review of hip labral tears. Current Reviews in Musculoskeletal Medicine 2(2): 105-117.

11. Robertson WJ, Kadrmas WR, Kelly BT (2007) Arthroscopic management of labral tears in the hip: A systematic review. Clinical Orthopaedics and Related Research 455: 88-92.

12. Saw T, Villar R (2004) Footballer's hip a report of six cases. The Bone and Joint Journal 86(5): 655-658.

13. Hunt D, Clohisy J, Prather H (2007) Acetabular tears of the hip in women. Physical Medicine and Rehabilitation Clinics of North America 18(3): 497-520

14. Toomayan GA, Holman WR, Major NM, Kozlowicz SM, Vail TP (2006) Sensitivity of MR arthrography in the evaluation of acetabular labral tears. American Journal of Roentgenology 186(2): 449-453.

15. Garrison JC, Osler MT, Singleton SB (2007) Rehabilitation after Arthroscopy of an Acetabular Labral Tear. North American Journal of Sports Physical Therapy 2(4): 241-250.

16. Yazbek PM, Ovanessian V, Martin RL, Fukuda TY (2011) Nonsurgical treatment of acetabular labrum tears: A case series. Journal of Orthopaedic \& Sports Physical Therapy 41(5): 346-353.

17. Hauser RA, Orlofsky A (2013) Regenerative Injection Therapy (Prolotherapy) for Hip Labrum Lesions: Rationale and Retrospective Study. Open Rehabilitation Journal 6: 59-68.

18. Schmerl M, Pollard H, Hoskins W (2005) Labral injuries of the hip: A review of diagnosis and management. Journal of Manipulative and Physiological Therapeutics 28(8): 632.e1-632.e8.

19. Kelly BT, Weiland DE, Schenker ML, Philippon MJ (2005) Arthroscopic labral repair in the hip: Surgical technique and review of the literature. Arthroscopy 21(12): 1496-1504.

20. Philippon M, Schenker M, Briggs K, Kuppersmith D (2007) Femoroacetabular impingement in 45 professional athletes: Associated pathologies and return to sport following arthroscopic decompression. Knee Surgery, Sports Traumatology, Arthroscopy 15(7): 908-914.

21. Byrd JT, Jones KS (2004) Diagnostic accuracy of clinical assessment, magnetic resonance imaging, magnetic resonance arthrography, and intra-articular injection in hip arthroscopy patients. The American journal of sports medicine 32(7): 1668-1674.

22. Meftah M, Rodriguez JA, Panagopoulos G, Alexiades MM (2011) Long-term results of arthroscopic labral debridement: Predictors of outcomes. Orthopedics 34(10): e588-e592.

23. Bedi A, Chen N, Robertson W, Kelly BT (2008) The management of labral tears and femoroacetabular impingement of the hip in the

This work is licensed under Creative

Commons Attribution 4.0 License

DOI: 10.19080/JPFMTS.2018.04.555636 young, active patient. Arthroscopy: The Journal of Arthroscopic \& Related Surgery 24(10): 1135-1145.

24. Schilders E, Dimitrakopoulou A, Bismil Q Marchant P, Cooke C (2011) Arthroscopic treatment of labral tears in femoroacetabular impingement: A comparative study of refixation and resection with a minimum two-year follow-up. The Bone and Joint Journal 93(8): 10271032.

25. Murphy KP, Ross AE, Javernick MA, Lehman Jr RA (2006) Repair of the adult acetabular labrum. Arthroscopy: The Journal of Arthroscopic \& Related Surgery 22(5): 567.e1-567.e3.

26. Larson CM, Giveans MR (2009) Arthroscopic debridement versus refixation of the acetabular labrum associated with femoroacetabular impingement. Arthroscopy 25(4): 369-376.

27. Greaves LL, Gilbart MK, Yung AC, Kozlowski P, Wilson DR (2010) Effect of acetabular labral tears, repair and resection on hip cartilage strain: A 7T MR study. Journal of biomechanics 43(5): 858-863.

28. Haddad B, Konan S, Haddad FS (2014) Debridement versus reattachment of acetabular labral tears: A review of the literature and quantitative analysis. Bone \& Joint Journal 96(1): 24-30.

29. Smart LR, Oetgen M, Noonan B, Medvecky M (2007) Beginning hip arthroscopy: Indications, positioning, portals, basic techniques, and complications. Arthroscopy: The Journal of Arthroscopic \& Related Surgery 23(12): 1348-1353.

30. Papavasiliou AV, Bardakos NV (2012) Complications of arthroscopic surgery of the hip. Bone and Joint Research 1(7): 131-144.

31. Safran MR (2010) The acetabular labrum: Anatomic and functional characteristics and rationale for surgical intervention. Journal of the American Academy of Orthopaedic Surgeons 18(6): 338-345.

32. Martin HD, Palmer IJ, Champlin K, Kaiser B, Kelly B, et al. (2012) Physiological changes as a result of hip arthroscopy performed with traction. Arthroscopy: The Journal of Arthroscopic \& Related Surgery 28(10): 1365-1372.

33. Bedi A, Kelly BT, Khanduja V (2013) Arthroscopic hip preservation surgery Current concepts and perspective. Bone \& Joint Journal 95(1): 10-19.

34. Diulus CA, Krebs VE, Hanna G, Barsoum WK (2006) Hip arthroscopy technique and indications. The Journal of Arthroplasty 21(4-1): 68-73.

35. Cheatham SW, Enseki KR, Kolber MJ (2014) Post-Operative Rehabilitation after Hip Arthroscopy: A Search for the Evidence. Journal of sport rehabilitation 24(4): 413-418.

36. Voight ML, Robinson K, Gill L, Griffin K (2010) Postoperative rehabilitation guidelines for hip arthroscopy in an active population. Sports Health: A Multidisciplinary Approach 2(3): 222-230.

Your next submission with Juniper Publishers will reach you the below assets

- Quality Editorial service

- Swift Peer Review

- Reprints availability

- E-prints Service

- Manuscript Podcast for convenient understanding

- Global attainment for your research

- Manuscript accessibility in different formats ( Pdf, E-pub, Full Text, Audio)

- Unceasing customer service

Track the below URL for one-step submission https://juniperpublishers.com/online-submission.php 